\title{
EFFECTS OF HEAT SOURCE/SINK AND CHEMICAL REACTION ON MHD MAXWELL NANOFLUID FLOW OVER A CONVECTIVELY HEATED EXPONENTIALLY STRETCHING SHEET USING HOMOTOPY ANALYSIS METHOD
}

\author{
C.S. SRAVANTHI \\ Department of Mathematics, The M.S. University of Baroda \\ Vadodara, Gujarat-390002, INDIA \\ E-mail: srinivasan_sravanthi@yahoo.com \\ R.S.R. GORLA \\ Department of Mechanical Engineering \\ Cleveland State University \\ Cleveland-44114, OHIO, USA
}

\begin{abstract}
The aim of this paper is to study the effects of chemical reaction and heat source/sink on a steady MHD (magnetohydrodynamic) two-dimensional mixed convective boundary layer flow of a Maxwell nanofluid over a porous exponentially stretching sheet in the presence of suction/blowing. Convective boundary conditions of temperature and nanoparticle concentration are employed in the formulation. Similarity transformations are used to convert the governing partial differential equations into non-linear ordinary differential equations. The resulting non-linear system has been solved analytically using an efficient technique, namely: the homotopy analysis method (HAM). Expressions for velocity, temperature and nanoparticle concentration fields are developed in series form. Convergence of the constructed solution is verified. A comparison is made with the available results in the literature and our results are in very good agreement with the known results. The obtained results are presented through graphs for several sets of values of the parameters and salient features of the solutions are analyzed. Numerical values of the local skin-friction, Nusselt number and nanoparticle Sherwood number are computed and analyzed.
\end{abstract}

Key words: HAM, chemical reaction, heat source/sink, Maxwell nanofluid, porous exponentially stretching sheet, convective boundary conditions.

\section{Introduction}

The boundary layer flows of non-Newtonian fluids driven by stretching surfaces have attracted much research interest [1-4] during the last few years due to several important engineering and industrial applications such as electronic chips, glass-fiber and paper production, food processing, etc. Single constitutive equation exhibiting all the properties of non-Newtonian fluids is not available due to the diversity of these fluids in their constitutive behavior, simultaneous viscous and elastic properties. Thus, several models of non-Newtonian fluids have been proposed to fit well with the experimental observations [5]. The non-Newtonian fluids can be classified into the following three types, i.e., (i) differential type (ii) rate type and (iii) integral type. The Maxwell fluid model, a simplest subclass of rate type fluids, describes the characteristics of the relaxation time. Thermoplastic polymers in the vicinity of their melting temperature, fresh concrete (neglecting its aging), numerous metals at a temperature close to their melting point, geomaterials, etc. behave typically as Maxwell fluids. The exact solutions of a fractional Maxwell

\footnotetext{
${ }^{*}$ To whom correspondence should be addressed
} 
model for a flow between two-sided wall perpendicular to a plate were presented by Vieru et al. [6], using Fourier and Laplace transforms. The unsteady flow in Maxwell fluids with the flow being induced by oscillating/accelerated nature of the rigid body was studied by Fetecau et al. [7-8]. Hayat et al. [9] studied the MHD unsteady flow of a Maxwell fluid in a rotating frame of reference and porous medium.

Suction or injection of a fluid through the bounding surface can significantly change the flow field. Injection of a fluid through a porous bounding wall is of general interest in practical problems involving boundary layer control applications such as film cooling, polymer fiber coating, and coating of wires. The process of suction and injection has also its importance in many engineering activities such as in the design of thrust bearings and radial diffusers, and thermal oil recovery. In chemical processes, suction is applied to remove reactants whereas injection is used to add reactants and reduce the drag.

The study of heat source/sink effects on heat transfer is very important because their effects are crucial in controlling the heat transfer. Bataller [10] studied the effects of heat source/sink, radiation and work done by deformation on flow and heat transfer of a viscoelastic fluid over a stretching sheet. Abel and Nandeppanavar [11] examined the effects of a non-uniform heat source in a viscoelastic boundary layer flow over a stretching sheet. Mukhopadhyay [12] made heat transfer analysis for an unsteady flow of a Maxwell fluid over a stretching surface in the presence of heat source/sink by using the shooting method.

The mass transfer phenomenon has applications in various scientific disciplines for different systems and mechanisms that involve molecular and convective transport of atoms and molecules. The transport of mass and momentum with chemical reactive species in the flow caused by a linear stretching sheet is discussed by Andersson et al. [13]. Cortell [14] investigated mass transfer with chemically reactive species for two classes of viscoelastic fluids over a porous stretching sheet. The effect of mass transfer on the stagnation point flow of an upper-convected Maxwell fluid is investigated by Hayat et al. [15]. Mukhopadhyay and Bhattacharyya [16] discussed the mass transfer effects on a Maxwell fluid flow past an unsteady stretching sheet.

The thermal conductivity rate of ordinary base fluids including water, ethylene glycol and oil is very low. But, nowadays the cooling of electronic devices is the major industrial requirement. To achieve this, the nanoscale solid particles are uniformly mixed with host fluids which change the thermophysical characteristics of these fluids and enhance the heat transfer rate dramatically. These fluids are said to be nanofluids. Choi [17]was the first who identified this colloidal suspension. The nanofluids have applications in cooling of electronics, heat exchangers, nuclear reactor safety, hyperthermia, biomedicine, engine cooling, vehicle thermal management and many others. Further, magneto nanofluids are useful in the manufacturing processes of gastric medications, biomaterials for wound treatment, sterilized devices, etc. Ethylene glycolAl2o3, ethylene glycol-Cuo and ethylene glycol-Zno are the examples of visco-elastic nanofluids. A bulk of research articles on nanofluids is available in the literature in which a few can be seen in the Refs. [18-24].

For many of the above mentioned problems, numerical techniques have been developed for years to obtain the accurate solution. But, due to some restrictions [25], scientists have considered analytical approaches as an alternative. The Homotopy Analysis Method (HAM) proposed by Liao [26], is a general analytical approach to obtain series solutions of strongly nonlinear equations which can provide us a simple way to ensure the convergence of solution series. Unlike numerical methods, it can be implemented with the boundary conditions at infinity. In numerical methods, the far field boundary conditions denoted by $\eta_{\max }$ must be chosen approximately for all computations as the computational domain has to be finite whereas the physical domain is unbounded.

No attempt has been made so far to analyze the MHD flow of a Maxwell nanofluid past an exponentially stretching surface with heat source/sink, chemical reaction effects under suction/blowing and convective boundary conditions. The present work aims to fill the gap in the existing literature. Hence, motivated by the above mentioned applications, an attempt is made to study the boundary layer MHD heat and mass transfer flow of a Maxwell nanofluid past an exponentially stretching sheet with heat source/sink, chemical reaction effects under suction/blowing and convective boundary conditions analytically via the Homotopy Analysis Method (HAM). The present problem (in the absence of the above mentioned effects) has recently been investigated numerically by Mustafa et. al. [27] only for a limited range of physical 
parameters by assuming $\eta_{\max }=2$. It is not surprising that their results are limited to only special parameters that are consistent with $\eta_{\max } \leq 2$. However, current results are independent to the value of $\eta_{\infty}$ and cover a wide range of physical parameters. In addition, the effects of non-dimensional parameters such as the magnetic parameter, heat source/sink parameter, chemical reaction parameter, skin friction, Nusselt number and nanoparticle Sherwood numbers have been discussed in detail.

\section{Formulation of the problem}

A steady two-dimensional incompressible boundary layer flow of a Maxwell nanofluid past a porous exponentially stretching sheet subject to a transverse magnetic field of strength $B_{0}$ in the presence of chemical reaction and heat source/sink effects is considered. The flow is assumed to be generated by stretching of the elastic boundary sheet from a slit with a large force such that the velocity of the boundary sheet is of an exponential order of the flow direction coordinate $\mathrm{x}$. The $\mathrm{x}$-axis is directed along the continuous stretching surface and points in the direction of the fluid motion while the y-axis is perpendicular to the surface. The flow is confined to $y>0$ (See Fig.1) [27, 31]. Here, the effect of the induced magnetic field is neglected. The Hall and electric field effects are neglected. Thermophorosis and Brownian motion effects are taken into account. We assume that the surface of the sheet is heated by convection from a hot fluid placed at the bottom of the sheet at temperature $T_{f}$ and concentration $C_{f}$ with heat and mass transfer coefficients $h_{1}$ and $h_{2}$. The equations governing such type of flow are written as [16, 27, 28, 32]

$$
\begin{aligned}
& \frac{\partial u}{\partial x}+\frac{\partial v}{\partial y}=0 \\
& u \frac{\partial u}{\partial x}+v \frac{\partial u}{\partial y}+\lambda_{I}\left(u^{2} \frac{\partial^{2} u}{\partial x^{2}}+v^{2} \frac{\partial^{2} u}{\partial y^{2}}+2 u v \frac{\partial^{2} u}{\partial x \partial y}\right)=v \frac{\partial^{2} u}{\partial y^{2}}-\frac{\sigma B_{0}^{2}}{\rho_{f}}\left(u+\lambda_{I} v \frac{\partial u}{\partial y}\right) \\
& u \frac{\partial T}{\partial x}+v \frac{\partial T}{\partial y}=\frac{k}{(\rho c)_{f}} \frac{\partial^{2} T}{\partial y^{2}}+\tau\left(D_{B} \frac{\partial C}{\partial y} \frac{\partial T}{\partial y}+\frac{D_{T}}{T_{\infty}}\left(\frac{\partial T}{\partial y}\right)^{2}\right)+Q\left(T-T_{\infty}\right) \\
& u \frac{\partial C}{\partial x}+v \frac{\partial C}{\partial y}=D_{B} \frac{\partial^{2} C}{\partial y^{2}}+\frac{D_{T}}{T_{\infty}} \frac{\partial^{2} T}{\partial y^{2}}-k_{r}\left(C-C_{\infty}\right)
\end{aligned}
$$

The boundary conditions for the present problem are $[27,33,34]$

$$
\begin{aligned}
& u=u_{w}(x), v=-V_{w}(x), \quad-k \frac{\partial T}{\partial y}=h_{1}\left(T_{f}-T\right), \quad-D_{B} \frac{\partial C}{\partial y}=h_{2}\left(C_{f}-C\right) \quad \text { at } \quad y=0, \\
& u \rightarrow 0, \quad T \rightarrow T_{\infty}, \quad C \rightarrow C_{\infty} \quad \text { as } \quad y \rightarrow \infty
\end{aligned}
$$

Here, $u_{w}=U e^{\frac{x}{L}}$ is the stretching velocity, $V_{w}(x)>0$ is the velocity of suction and $V_{w}(x)<0$ is the velocity of blowing, $V_{w}(x)=V_{0} e^{\frac{x}{2 L}}$ [35] is a special type of velocity at the wall, $h_{l}=h_{f} e^{\frac{x}{2 L}}$ is the heat 
transfer coefficient, $h_{2}=h_{m} e^{\frac{x}{2 L}}$ is the mass transfer coefficient, $Q=\frac{1}{2} Q_{0} e^{\frac{x}{L}}$ is the variable volumetric rate of heat generation (i.e., heat source) or heat absorption (i.e., heat sink), where $Q_{0}$ is a constant having the same dimension as $Q, k_{r}=\frac{1}{2} k_{0} e^{\frac{x}{L}}$ [35] is the variable rate of chemical conversion of the first order irreversible reaction, where $k_{0}$ is a constant having the same dimension as $k$, the diffusivity of the species can either be destroyed or generated in the reaction.

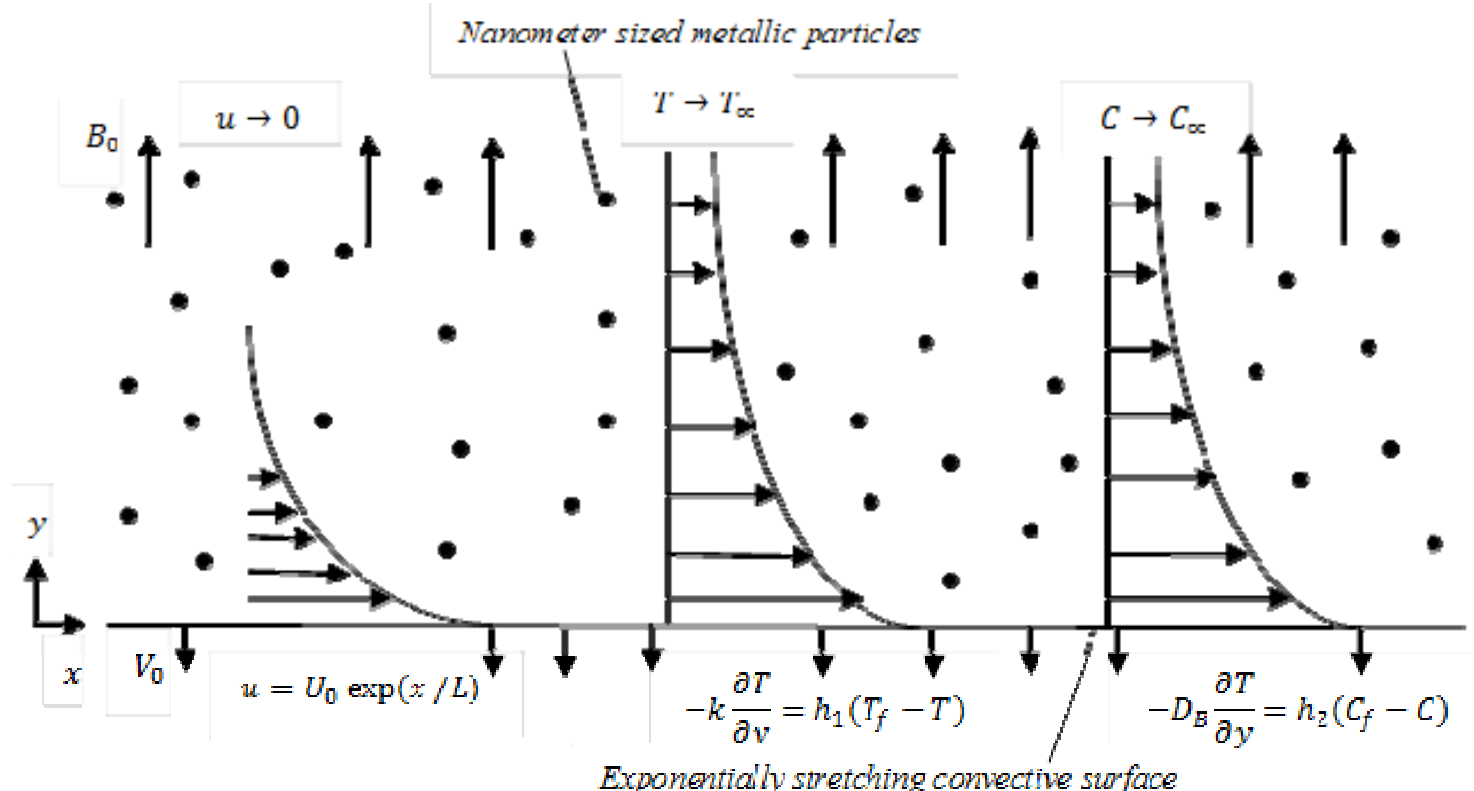

Fig.1. Physical model and coordinate system of the problem.

\subsection{Method of solution}

Introducing the similarity variables [27] as

$$
\begin{aligned}
& \eta=\sqrt{\frac{U_{0}}{2 v L}} e^{\frac{x}{2 L} y}, u=U f^{\prime}(\eta) e^{\frac{x}{L}}, v=-e^{\frac{x}{2 L}} \sqrt{\frac{v U_{0}}{2 L}}\left(f+\eta f^{\prime}\right), \\
& \theta(\eta)=\frac{T-T_{\infty}}{T_{f}-T_{0}}, \quad \phi(\eta)=\frac{C-C_{\infty}}{C_{f}-C_{0}}
\end{aligned}
$$

Using Eqs (2.6), Eqs (2.2)-(2.4) reduce to

$$
\begin{aligned}
& f^{\prime \prime \prime}+f f^{\prime \prime}-2(f)^{2}+\lambda\left(3 f f f^{\prime \prime}+\frac{\eta}{2} f^{\prime 2} f^{\prime \prime}-\frac{1}{2} f^{2} f^{\prime \prime \prime}-2 f^{\prime 3}\right)-M\left(f^{\prime}-\frac{\lambda}{2}\left(f+\eta f^{\prime}\right) f^{\prime \prime}\right)=0 \\
& \frac{1}{\operatorname{Pr}} \theta^{\prime \prime}+N b \theta^{\prime} \phi^{\prime}+N t \theta^{\prime 2}+f \theta^{\prime}+Q_{H} \theta=0,
\end{aligned}
$$




$$
\phi^{\prime \prime}+\operatorname{Sc} f \phi^{\prime}+\frac{N t}{N b} \theta^{\prime \prime}-\operatorname{Sc} \beta \phi=0
$$

and the corresponding boundary conditions are

$$
\begin{aligned}
& f^{\prime}=1, \quad f=S, \quad \theta^{\prime}=-\gamma_{1}(1-\theta), \quad \phi^{\prime}=-\gamma_{2}(1-\phi) \quad \text { at } \quad \eta=0, \\
& f^{\prime} \rightarrow 0, \quad \theta \rightarrow 0, \quad \phi \rightarrow 0 \quad \text { as } \quad \eta \rightarrow \infty
\end{aligned}
$$

where $M=\frac{2 L \sigma B_{0}^{2}}{U \rho e^{\frac{x}{L}}}$ is the local magnetic parameter, $\lambda=\frac{\operatorname{Re}_{x} \lambda_{1} \mathrm{v}}{2 L^{2}}$ is the local Deborah number, $N b=\frac{\tau D_{B} C_{\infty}}{\mathrm{v}}$ is the Brownian motion parameter, $N t=\frac{\tau D_{T}\left(T_{f}-T_{\infty}\right)}{T_{\infty} v}$ is the thermophoresis parameter, $\operatorname{Pr}=\frac{v(\rho c)_{f}}{k}$ is the Prandtl number, $S=\frac{V_{0}}{\sqrt{\frac{v U}{2 L}}}$ is the suction $(\mathrm{S}>0) /$ blowing $(\mathrm{S}<0)$ parameter, $\beta=\frac{K_{0} L}{U}$ is the chemical reaction parameter where $\beta>0$ indicates a destructive chemical reaction, $\beta<0$ denotes a generative chemical reaction, and $\beta=0$ represents the nonreactive species, $Q_{H}=\frac{Q_{0} L}{U_{0}}$ is the heat source $\left(Q_{H}>0\right) /$ sink $\left(Q_{H}<0\right)$ parameter, $\mathrm{Sc}=\frac{v}{D_{B}}$ is the Schmidt number, $\gamma_{1}=\frac{h_{1}}{k \sqrt{\frac{U}{2 v L}}}$ is the heat transfer Biot number, $\gamma_{2}=\frac{h_{2}}{D_{B} \sqrt{\frac{U}{2 v L}}}$ mass transfer Biot number and $\operatorname{Re}=\frac{2 U e^{\frac{x}{L}} L}{v}$ is the local Reynolds number. as

The local skin-friction, Nusselt number and nanoparticle Sherwood number can be defined [27, 32]

$$
C_{f}=\frac{\tau_{w}}{\rho U_{w}^{2}}, \quad \mathrm{Nu}=\frac{x q_{w}}{k\left(T_{f}-T_{\infty}\right)}, \quad \mathrm{Sh}=\frac{x q_{m}}{D_{B}\left(C_{f}-C_{\infty}\right)}
$$

Here, $\tau_{w}$ is the surface shear stress and $q_{w}, q_{m}$ are the heat flux and nanoparticle mass flux at the surface, respectively, and are defined as follows

$$
\tau_{w}=\left.\mu \frac{\partial u}{\partial y}\right|_{y=0}, \quad q_{w}=-\left.k \frac{\partial T}{\partial y}\right|_{y=0}, \quad q_{m}=-\left.D_{B} \frac{\partial C}{\partial y}\right|_{y=0} .
$$

It is worth mentioning that using dimensionless variables, the skin friction and Nusselt number and nanoparticle mass transfer can be written as 


$$
C_{f} \sqrt{\mathrm{Re}}=f^{\prime \prime}(0), \quad \frac{\mathrm{Nu}}{\sqrt{\operatorname{Re}}} \frac{2 L}{x}=-\theta^{\prime}(0), \quad \frac{\mathrm{Sh}}{\sqrt{\operatorname{Re}}} \frac{2 L}{x}=-\theta^{\prime}(0) .
$$

In the present context, $C_{f} \sqrt{\mathrm{Re}}, \frac{\mathrm{Nu}}{\sqrt{\mathrm{Re}}} \frac{2 L}{x}$ and $\frac{\mathrm{Sh}}{\sqrt{\mathrm{Re}}} \frac{2 L}{x}$ are referred to as the reduced skin friction coefficient, reduced Nusselt number and reduced nanoparticle Sherwood number which are represented by $f^{\prime \prime}(0),-\theta^{\prime}(0)$ and $-\phi^{\prime}(0)$. Our task is to investigate how the values of $f^{\prime \prime}(0),-\theta^{\prime}(\eta)$ and $-\phi^{\prime}(\eta)$ vary with the pertinent parameters of the present problem.

\section{Series solution by HAM}

The first step in the HAM is to find a set of base functions to express the solution of the problem under investigation. Here, due to boundary layer flows which are decaying exponentially at infinity, we assume that $f(\eta), \theta(\eta)$ and $\phi(\eta)$ can be expressed by a set of base functions

$$
\left\{\eta^{k} \exp (-n \eta) k / k \geq 0, \quad n \geq 0\right\}
$$

in the form

$$
\begin{aligned}
& f(\eta)=a_{0,0}+\sum_{k=0}^{+\infty} \sum_{n=1}^{+\infty} a_{k, n} \eta^{k} \exp (-n \eta), \\
& \theta(\eta)=\sum_{k=0}^{+\infty} \sum_{n=0}^{+\infty} b_{k, n} \eta^{k} \exp (-n \eta), \\
& \phi(\eta)=\sum_{k=0}^{+\infty} \sum_{n=0}^{+\infty} c_{k, n} \eta^{k} \exp (-n \eta)
\end{aligned}
$$

where $a_{k, n}, b_{k, n}$ and $c_{k, n}$ are coefficients. Thus, all the approximations of $f(\eta), \theta(\eta)$ and $\phi(\eta)$ must obey the above expressions. This is called the rule of solution expression for $f(\eta), \theta(\eta)$ and $\phi(\eta)$. According to the boundary conditions (2.10) and the rule of solution expression defined by Eq.(3.2), we choose

$$
\begin{aligned}
& f_{0}(\eta)=S+1-\exp (-\eta), \\
& \theta_{0}(\eta)=\frac{\gamma_{1}}{1+\gamma_{1}} \exp (-\eta), \\
& \phi_{0}(\eta)=\frac{\gamma_{2}}{1+\gamma_{2}} \exp (-\eta)
\end{aligned}
$$

as the initial approximations of $f(\eta), \theta(\eta)$ and $\phi(\eta)$. Besides, we select the auxiliary linear operators $L_{f}(f), L_{\theta}(\theta)$ and $L_{\phi}(\phi)$, which are the linear parts of the respective equations, as 


$$
\begin{aligned}
& L_{f}(f)=\frac{d^{3} f}{d \eta^{3}}-\frac{d f}{d \eta}, \\
& L_{\theta}(\theta)=\frac{d^{2} \theta}{d \eta^{2}}-\theta, \\
& L_{\phi}(\phi)=\frac{d^{2} \phi}{d \eta^{2}}-\phi,
\end{aligned}
$$

satisfying the following properties

$$
\begin{aligned}
& L_{f}\left(C_{1}+C_{2} \exp (\eta)+C_{3} \exp (-\eta)\right)=0, \\
& L_{\theta}\left(C_{4} \exp (\eta)+C_{5} \exp (-\eta)\right)=0 \\
& L_{\phi}\left(C_{6} \exp (\eta)+C_{7} \exp (-\eta)\right)=0
\end{aligned}
$$

where $C_{i}, i=1-7$, are constants.

Zeroth-order deformation problem

$$
\begin{aligned}
& (1-p) L_{f}\left[f(\eta ; p)-f_{0}(\eta)\right]=p \hbar_{f} N_{f}[f, \theta, \phi], \\
& (1-p) L_{\theta}\left[\theta(\eta ; p)-\theta_{0}(\eta)\right]=p \hbar_{\theta} N_{\theta}[f, \theta, \phi] \\
& (1-p) L_{\phi}\left[\phi(\eta ; p)-\phi_{0}(\eta)\right]=p \hbar_{\phi} N_{\phi}[f, \theta, \phi]
\end{aligned}
$$

where $p \in[0,1]$ denotes the embedding parameter and $\hbar$ indicates the non-zero auxiliary parameter and

$$
\begin{aligned}
& N_{f}[f, \theta, \phi]=\frac{\partial^{3} f(\eta, p)}{\partial \eta^{3}}+f(\eta, p) \frac{\partial^{2} f(\eta, p)}{\partial \eta^{2}}-2\left(\frac{\partial f(\eta, p)}{\partial \eta}\right)^{2}+ \\
& +\lambda\left[3 f(\eta, p) \frac{\partial f(\eta, p)}{\partial \eta} \frac{\partial^{2} f(\eta, p)}{\partial \eta^{2}}+\frac{\eta}{2}\left(\frac{\partial f(\eta, p)}{\partial \eta}\right)^{2} \frac{\partial^{2} f(\eta, p)}{\partial \eta^{2}}+\right. \\
& \left.-\frac{1}{2}(f(\eta, p))^{2} \frac{\partial^{3} f(\eta, p)}{\partial \eta^{3}}-2\left(\frac{\partial f(\eta, p)}{\partial \eta}\right)^{3}\right]+ \\
& -M\left(\frac{\partial f(\eta, p)}{\partial \eta}-\frac{\lambda}{2}\left(f(\eta, p)+\eta \frac{\partial f(\eta, p)}{\partial \eta}\right) \frac{\partial^{2} f(\eta, p)}{\partial \eta^{2}}\right)
\end{aligned}
$$




$$
\begin{aligned}
& N_{\theta}[f, \theta, \phi]=\frac{1}{\operatorname{Pr}} \frac{\partial^{2} \theta(\eta, p)}{\partial \eta^{2}}+N b \frac{\partial \theta(\eta, p)}{\partial \eta} \frac{\partial \phi(\eta, p)}{\partial \eta}+ \\
& +N t\left(\frac{\partial \theta(\eta, p)}{\partial \eta}\right)^{2}+f(\eta, p) \frac{\partial \theta(\eta, p)}{\partial \eta}-Q_{H} \theta(\eta, p), \\
& N_{\phi}[f, \theta, \phi]=\frac{\partial^{2} \phi(\eta, p)}{\partial \eta^{2}}+\operatorname{Sc} f(\eta, p) \frac{\partial \phi(\eta, p)}{\partial \eta}+\frac{N t}{N b} \frac{\partial^{2} \theta(\eta, p)}{\partial \eta^{2}}-\operatorname{Sc} \beta \phi(\eta, p) .
\end{aligned}
$$

Subject to the following boundary conditions

$$
\begin{aligned}
& f(0, p)=S, f^{\prime}(0, p)=1, f^{\prime}(\infty, p)=0, \\
& \theta^{\prime(0, p)}=-\gamma_{1}(1-\theta(0, p)), \theta(\infty, p)=0, \\
& \phi^{\prime}(0, p)=-\gamma_{2}(1-\phi(0, p)), \phi(\infty, p)=0,
\end{aligned}
$$

mth-order deformation problems

Differentiating $m$-times the zeroth-order deformation problems (3.6) with respect to $p$, then dividing by $m$ ! and setting $p=0$, we get the following higher-order deformation problems

$$
\begin{aligned}
& L_{f}\left[f_{m}(\eta)-\chi_{m} f_{m-1}(\eta)\right]=\hbar_{f} R_{m}^{f}(\eta), \\
& L_{\theta}\left[\theta_{m}(\eta)-\chi_{m} \theta_{m-1}(\eta)\right]=\hbar_{\theta} R_{m}^{\theta}(\eta), \\
& L_{\phi}\left[\phi_{m}(\eta)-\chi_{m} \phi_{m-1}(\eta)\right]=\hbar_{\phi} R_{m}^{\phi}(\eta),
\end{aligned}
$$

and the boundary conditions are

$$
\begin{aligned}
& f_{m}(0)=0, f_{m}{ }^{\prime}(0)=0, f_{m}{ }^{\prime}(\infty)=0, \\
& \theta_{m}{ }^{\prime}(0)=\gamma_{l} \theta_{m}(0), \theta_{m}(\infty)=0, \\
& \phi_{m}{ }^{\prime}(0)=\gamma_{2} \phi_{m}(0), \phi_{m}(\infty)=0
\end{aligned}
$$

where

$$
f_{m}(\eta)=\frac{1}{m !} \frac{\partial^{m} f(\eta, p)}{\partial \eta^{m}}, \quad \theta_{m}(\eta)=\frac{1}{m !} \frac{\partial^{m} \theta(\eta, p)}{\partial \eta^{m}}, \quad \phi_{m}(\eta)=\frac{1}{m !} \frac{\partial^{m} \phi(\eta, p)}{\partial \eta^{m}},
$$




$$
\begin{aligned}
& R_{m}^{f}(\eta)=f_{m-1}^{\prime \prime \prime}+\sum_{n=0}^{m-1} f_{m-1-n} f_{n}^{\prime \prime}-2 \sum_{n=0}^{m-1} f_{m-1-n}^{\prime} f_{n}^{\prime} \lambda\left(\sum _ { k = 0 } ^ { m - 1 } \sum _ { l = 0 } ^ { k } \left(3 f_{m-1-k} f_{k-l}^{\prime} f_{l}^{\prime \prime}+\frac{\eta}{2} f^{\prime}{ }_{m-l-k} f_{k-l}^{\prime} f_{l}^{\prime \prime}+\right.\right. \\
& \left.\left.-\frac{1}{2} f_{m-1-k} f_{k-l} f_{l}^{\prime \prime \prime}-2 f^{\prime}{ }_{m-1-k} f_{k-l}^{\prime} f_{l}^{\prime}\right)\right)-M\left(f^{\prime}{ }_{m-1}-\frac{\lambda}{2} \sum_{n=0}^{m-1}\left(f_{m-1-n} f_{n}^{\prime \prime}+\eta f_{m-1-n}^{\prime} f_{n}^{\prime \prime}\right)\right)=0 \\
& R_{m}^{\theta}(\eta)=\frac{1}{P r} \theta_{m-1}^{\prime \prime}+N b \sum_{n=0}^{m-1} \theta_{m-1-n}^{\prime} \phi_{n}^{\prime}+N t \sum_{n=0}^{m-1} \theta_{m-1-n}^{\prime} \theta_{n}^{\prime}+\sum_{n=0}^{m-1} f_{m-1-n} \theta_{n}^{\prime}+Q_{H} \theta_{m-1}=0 \\
& R_{m}^{\phi}(\eta)=\phi_{m-1}^{\prime \prime}+\operatorname{Sc} \sum_{n=0}^{m-1} f_{m-1-n} \phi_{n}^{\prime}+\frac{N t}{N b} \theta_{m-1}^{\prime \prime}-\operatorname{Sc} \beta \phi_{m-1}=0
\end{aligned}
$$

and

$$
\chi_{m}= \begin{cases}0 & m \leq 1 \\ 1 & m \geq 1\end{cases}
$$

For $p=0$ and $p=1$, we can write

$$
\begin{array}{ll}
f(\eta, 0)=f_{0}(\eta), & f(\eta, l)=f(\eta), \\
\theta(\eta, 0)=\theta_{0}(\eta), & \theta(\eta, 1)=\theta(\eta), \\
\phi(\eta, 0)=\phi_{0}(\eta), & \phi(\eta, 1)=\phi(\eta),
\end{array}
$$

and with variation of $p$ from 0 to $1, f(\eta, p), \theta(\eta, p)$ and $\phi(\eta, p)$ vary from initial solutions $f_{0}(\eta), \theta_{0}(\eta)$ and $\phi_{0}(\eta)$ to final solutions $f(\eta), \theta(\eta)$ and $\phi(\eta)$ respectively. By Taylor's series we have

$$
\begin{array}{ll}
f(\eta, p)=f_{0}(\eta)+\sum_{m=1}^{\infty} f_{m}(\eta) p^{m}, & f_{m}(\eta)=\left.\frac{1}{m !} \frac{\partial^{m} f(\eta, p)}{\partial \eta^{m}}\right|_{p=0}, \\
\theta(\eta, p)=\theta_{0}(\eta)+\sum_{m=1}^{\infty} \theta_{m}(\eta) p^{m}, & \theta_{m}(\eta)=\left.\frac{1}{m !} \frac{\partial^{m} \theta(\eta, p)}{\partial \eta^{m}}\right|_{p=0}, \\
\phi(\eta, p)=\phi_{0}(\eta)+\sum_{m=1}^{\infty} \phi_{m}(\eta) p^{m}, & \phi_{m}(\eta)=\left.\frac{1}{m !} \frac{\partial^{m} \phi(\eta, p)}{\partial \eta^{m}}\right|_{p=0} .
\end{array}
$$

The value of the auxiliary parameter is chosen in such a way that these three series (3.15)-(3.17) are convergent at $p=1$.

Eqs (3.9) represents the system of non-homogeneous linear differential equations whose general solutions are the sum of complementary and particular solutions which can be expressed as 


$$
\begin{aligned}
& f_{m}(\eta)=f_{m}^{*}(\eta)+C_{1}^{m}+C_{2}^{m} e^{\eta}+C_{3}^{m} e^{-\eta}, \\
& \theta_{m}(\eta)=\theta_{m}^{*}(\eta)+C_{4}^{m} e^{\eta}+C_{5}^{m} e^{-\eta}, \\
& \phi_{m}(\eta)={\phi_{m}}^{*}(\eta)+C_{6}^{m} e^{\eta}+C_{7}^{m} e^{-\eta}
\end{aligned}
$$

where the constants $C_{i}^{m}(i=1,2, . .7)$, considering the boundary conditions Eqs (3.10) are

$$
\begin{aligned}
& C_{2}^{m}=C_{4}^{m}=C_{6}^{m}=0, \\
& C_{1}^{m}=-C_{3}^{m}-f_{m}{ }^{*}(0), \\
& C_{3}^{m}=f_{m}{ }^{*}(0), \\
& C_{5}^{m}=\frac{1}{1+\gamma_{1}}\left[\theta_{m}{ }^{*}(0)-\gamma_{1} \theta_{m}{ }^{*}(0)\right], \\
& C_{7}^{m}=\frac{1}{1+\gamma_{2}}\left[\phi_{m}{ }^{*}{ }^{\prime}(0)-\gamma_{2} \phi_{m}{ }^{*}(0)\right] .
\end{aligned}
$$

\section{Convergence analysis}

In the HAM method, it is essential to ensure the convergence of our series solution. As pointed by Liao [30], the convergence rate of approximation for the HAM solution strongly depends on the value of the auxiliary parameter $\hbar$. This auxiliary parameter provides us great freedom to adjust and control the convergence region of the series solution. Hence, in order to seek the permissible values of $\hbar_{f}, \hbar_{\theta}$ and $\hbar_{\phi}$ the functions of $f^{\prime \prime}(0), \theta^{\prime}(0)$ and $\phi^{\prime}(0)$ are plotted at $20^{\text {th }}$-order of approximations. The values of $\hbar_{f}, \hbar_{\theta}$ and $\hbar_{\phi}$ are selected in such a way that curves are parallel to the horizontal axis i.e., $\hbar-$ axis [30]. Figures 2-4, clearly depict the acceptable range for values of $\hbar_{f}\left(-0.6<\hbar_{f}<-0.1\right), \hbar_{\theta}\left(-0.6<\hbar_{\theta}<-0.1\right)$ and $\hbar_{\phi}\left(-0.8<\hbar_{\phi}<-0.1\right)$. The current calculations are based on the value of $\hbar_{f}=\hbar_{\theta}=\hbar_{\phi}=-0.4$. In order to ensure the convergence of solutions, Tab.1 is given. This table clearly shows that the convergence is obtained at $35^{\text {th }}$ order of approximations. 


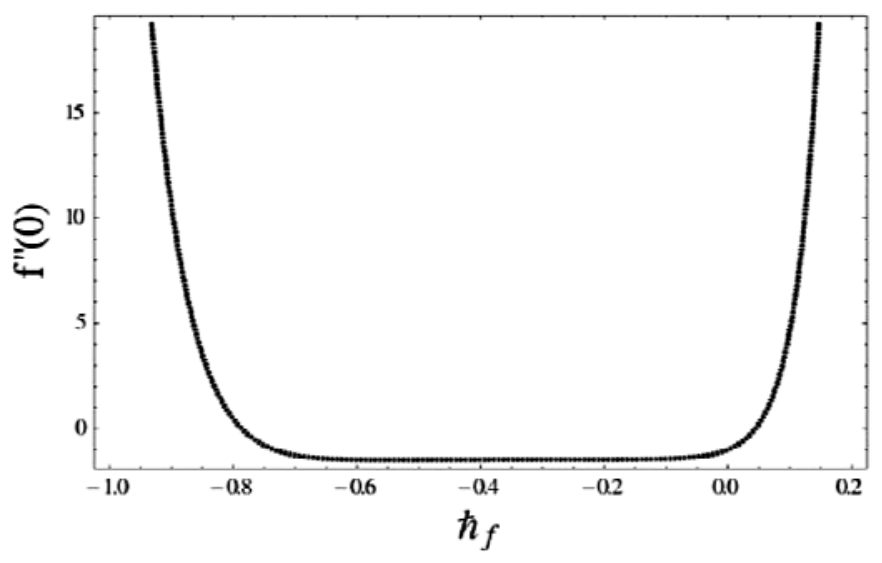

Fig.2. $\hbar$ curve for $f$ at $20^{\text {th }}$ order of approximation.

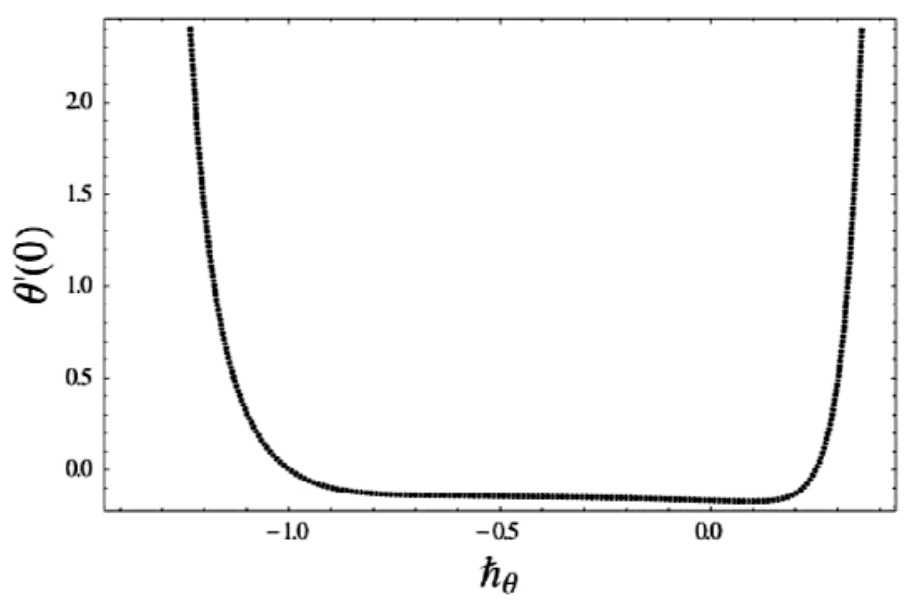

Fig.3. $\hbar$ curve for $\theta$ at $20^{\text {th }}$ order of approximation.

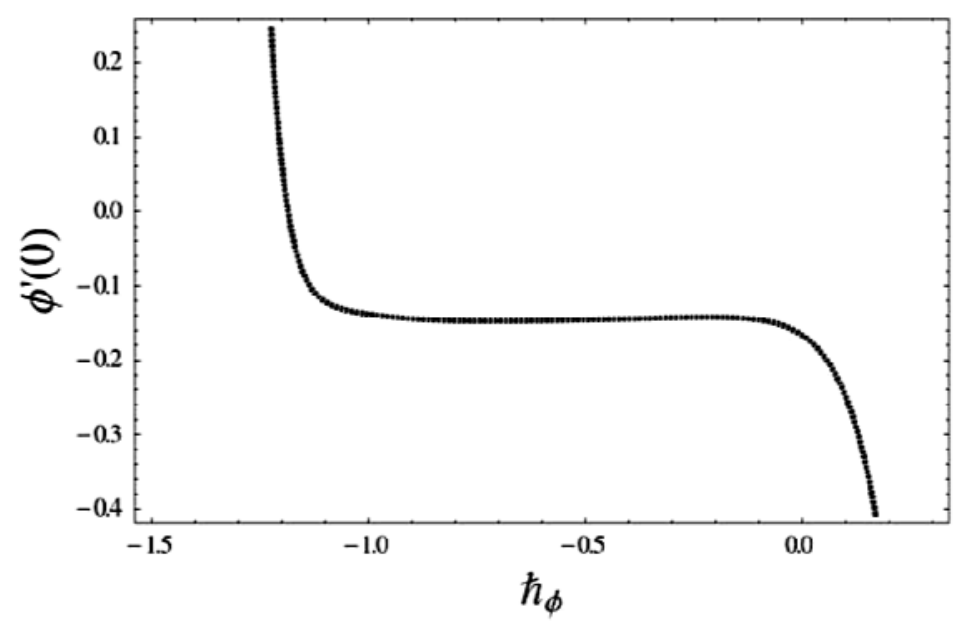

Fig.4. $\hbar$ curve for $\phi$ at $20^{\text {th }}$ order of approximation. 
Table 1. Convergence of HAM solution for $f^{\prime \prime}(0), \theta^{\prime}(0)$ and $\phi^{\prime}(0)$ when $\lambda=0.2, \mathrm{M}=0.2, \operatorname{Pr}=10$, $\mathrm{Nb}=\mathrm{Nt}=0.5, \mathrm{QH}=0.2, \mathrm{Sc}=20, \beta=0.5, S=0, \gamma_{1}=\gamma_{2}=0.2, \hbar_{f}=\hbar_{\theta}=\hbar_{\phi}=-0.4$.

\begin{tabular}{cccc}
\hline $\begin{array}{c}\text { Order of } \\
\text { approximation }\end{array}$ & $-f^{\prime \prime}(0)$ & $-\theta^{\prime}(0)$ & $-\phi^{\prime}(0)$ \\
\hline 1 & 1.2414 & 0.1652 & 0.1587 \\
5 & 1.4554 & 0.1599 & 0.1447 \\
10 & 1.4742 & 0.1543 & 0.1420 \\
15 & 1.4754 & 0.1501 & 0.1430 \\
20 & 1.4754 & 0.1467 & 0.1445 \\
25 & 1.4754 & 0.1442 & 0.1458 \\
30 & 1.4754 & 0.1410 & 0.1469 \\
34 & 1.4754 & 0.1408 & 0.1478 \\
35 & 1.4754 & 0.1408 & 0.1478 \\
\hline
\end{tabular}

\section{Results and discussion}

To clearly provide a physical insight to the heat and mass transfer of a Maxwell nanofluid in the presence of heat source/sink and chemical reaction effects, computations have been carried out using the method described in the previous section for variations in the governing parameters and the results are illustrated graphically in Figs 5-20. In the present study, the following default parameter values are adopted for computations: $\lambda=1, M=0.1, \operatorname{Pr}=10, N b=0.5, N t=0.5, Q_{H}=0.5, \mathrm{Sc}=20, \quad \beta=0.5, S=0, \quad \gamma_{1}=0.5$, $\gamma_{2}=0.5$. All graphs and tables as therefore correspond to these values unless otherwise stated.

For the verification of accuracy of the applied HAM, a comparison of the present results corresponding to the values of $\left[\theta^{\prime}(0)\right]$ with the available published results of Magyari and Keller [36], Mustafa et al. [27] in the case of a regular fluid is made numerically and presented in Tab.2. The results are in excellent agreement. Therefore, we are confident that the present results are accurate.

Table 2. Comparison of numerical values of $\left[\theta^{\prime}(0)\right]$ with previous studies in the case of regular fluid when $\lambda=0$.

\begin{tabular}{cccc}
\hline $\operatorname{Pr}$ & Magyari and Keller [36] & Mustafa et al.[27] & Present \\
\hline 3 & -1.1222 & -1.1221 & -1.1210 \\
5 & -1.5212 & -1.5212 & -1.5200 \\
8 & -1.9918 & -1.9918 & -1.9910 \\
10 & -2.2574 & -2.2574 & -2.2570 \\
\hline
\end{tabular}

Figures 5-7 shows the profiles of velocity, temperature and nanoparticle volume fraction for different values of the local magnetic parameter $M$. It is clear from Fig.5 that an increase in $M$ decreases velocity, throughout the boundary layer flow field. It is because the application of a transverse magnetic field will result in a resistive type force (Lorentz force which opposes the flow) and thus reduces the velocity. It is evident from Fig.6 and Fig.7 that an increase in the local magnetic parameter $M$ increases the temperature as well as nanoparticle volume fraction. This is due to the fact that Lorentz force tends to resist the flow and this resistance offered to the flow is responsible for broadening the thermal and concentration boundary layer thicknesses. 


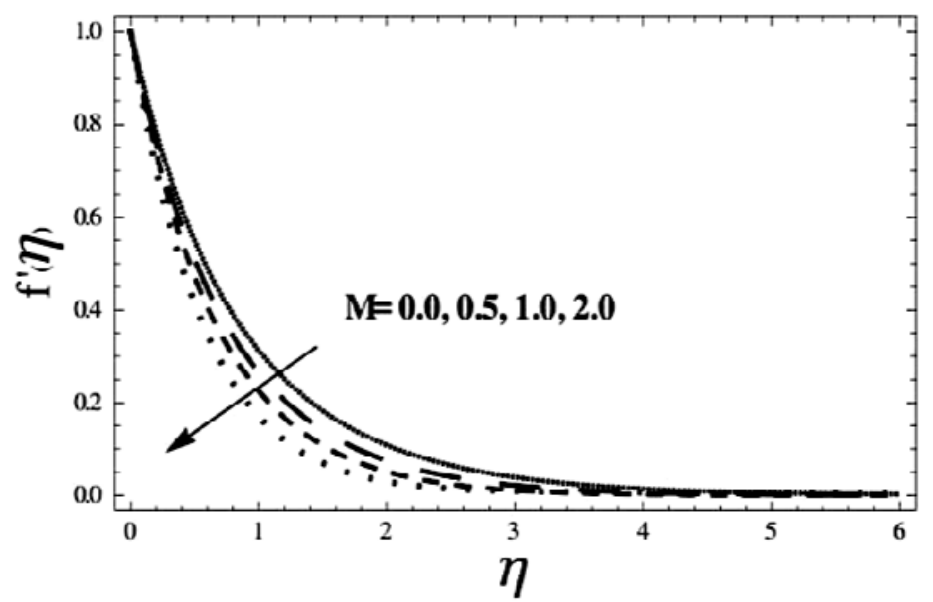

Fig.5. Effect of $M$ on velocity.

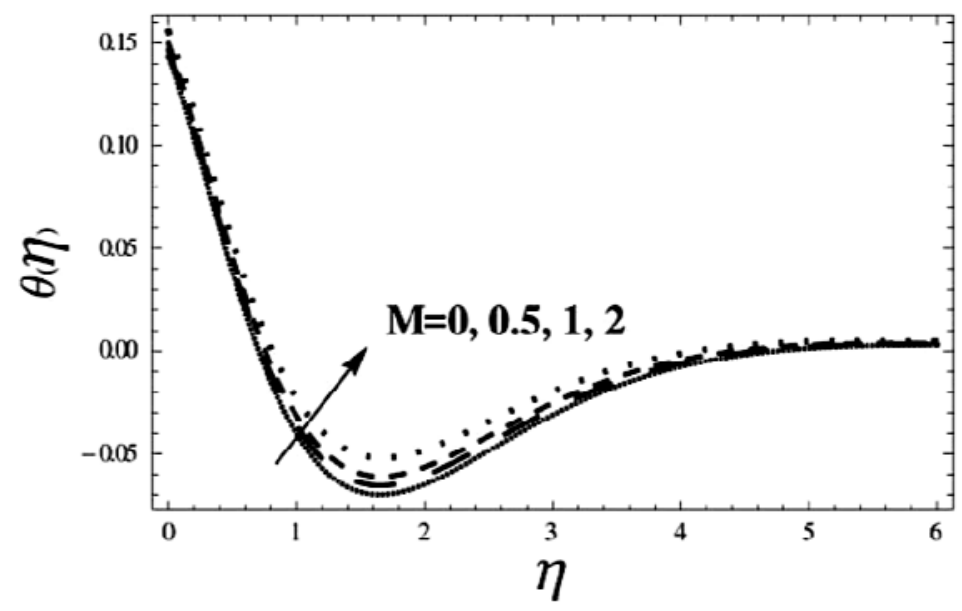

Fig.6. Effect of $M$ on temperature.

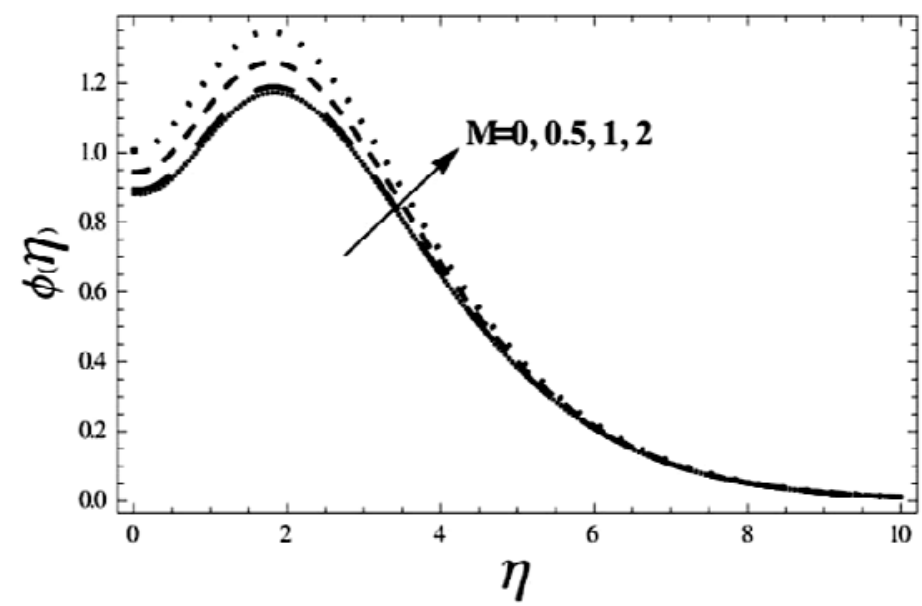

Fig.7. Effect of $M$ on nanoparticle volume fraction. 
Figures 8-10 display the effect of the suction/blowing parameter $S$ on velocity, temperature and volume fraction of the nanofluid, respectively, in the presence of convection at the boundary for an exponentially stretching sheet. It is observed that velocity decreases significantly with increasing suction $(S>0)$ but increases with increasing blowing $(S<0)$ (Fig.8). When the wall suction $(S>0)$ is considered, this causes a decrease in the boundary layer thickness and the velocity field is reduced. $S=0$ represents the case of a non-porous stretching sheet. It is known that imposition of wall suction $(S>0)$ has the tendency to reduce the momentum boundary layer thickness, which causes reduction in the velocity. The opposite is noted for blowing $(S<0)$. This is due to the fact that when stronger blowing is provided, the fluid is pushed farther from the wall where due to a smaller influence of viscosity, the flow is accelerated. This effect increases the maximum velocity within the boundary layer. The same principle operates but in the reverse direction in the case of suction. Figures 9 and 10 represent the profiles of temperature and nanoparticle volume fraction, respectively, for the variable suction/blowing parameter $S$. It is evident that the fluid velocity, temperature and volume fractions are larger in the case of blowing compared to suction. It is also noted that the velocity, temperature and the volume fractions of the nanofluid in the absence of suction/blowing are greater compared to the case of a nanofluid with suction but smaller compared to the case of a nanofluid with injection.

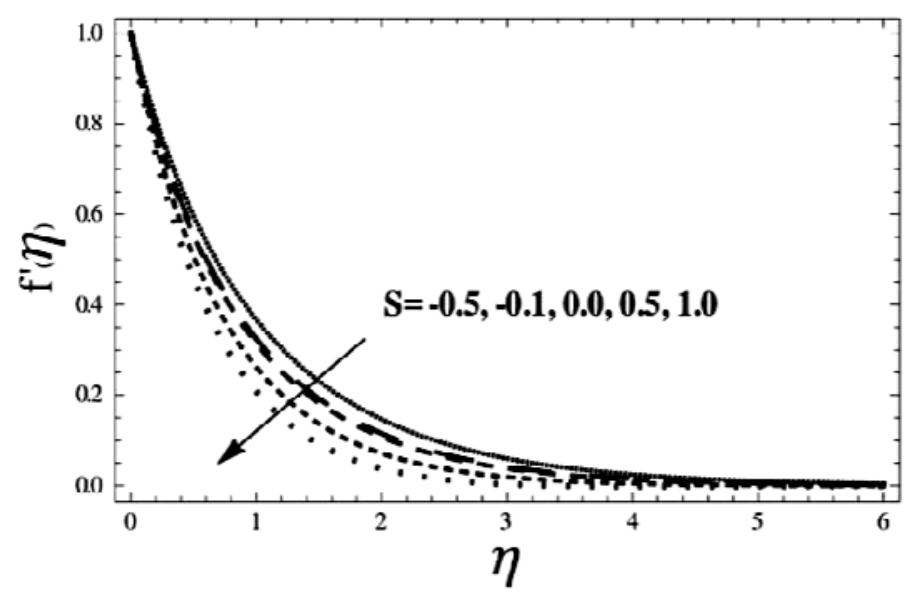

Fig.8. Effect of $S$ on velocity.

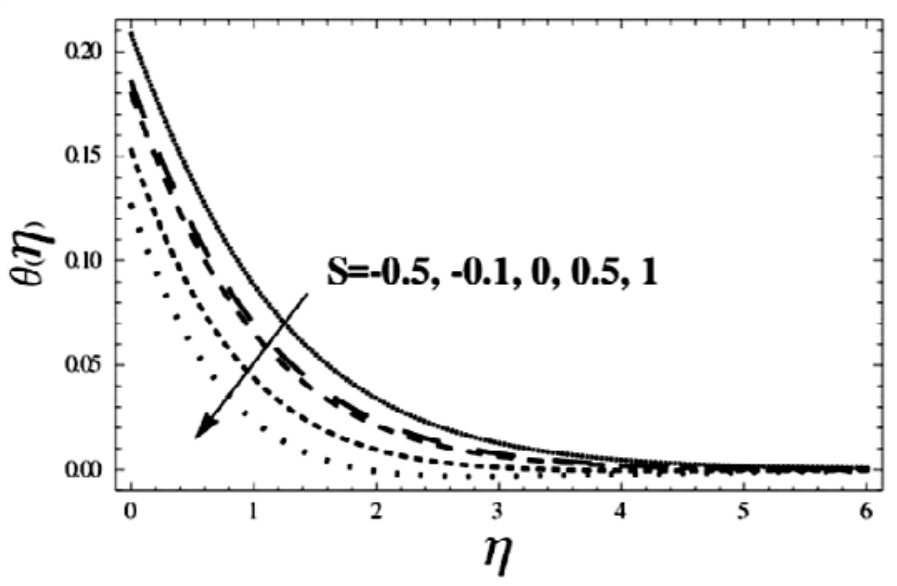

Fig.9. Effect of $S$ on temperature. 
Figure 11 illustrates the influence of the heat generation (source) $\left(Q_{H}>0\right)$ /absorption (sink) $\left(Q_{H}<0\right)$ parameter $Q_{H}$ on the temperature. It is seen from the figure that the temperature decreases with increasing heat absorption $\left(Q_{H}<0\right)$ but increases with increasing heat generation $\left(Q_{H}>0\right)$. This is due to the fact that the thermal boundary layer generates energy, which causes the temperature profiles to increase with increasing values of $Q_{H}>0$. However, in the case of $Q_{H}<0$, the boundary layer energy is absorbed, resulting in a considerable temperature fall with the decreasing values of $Q_{H}$.

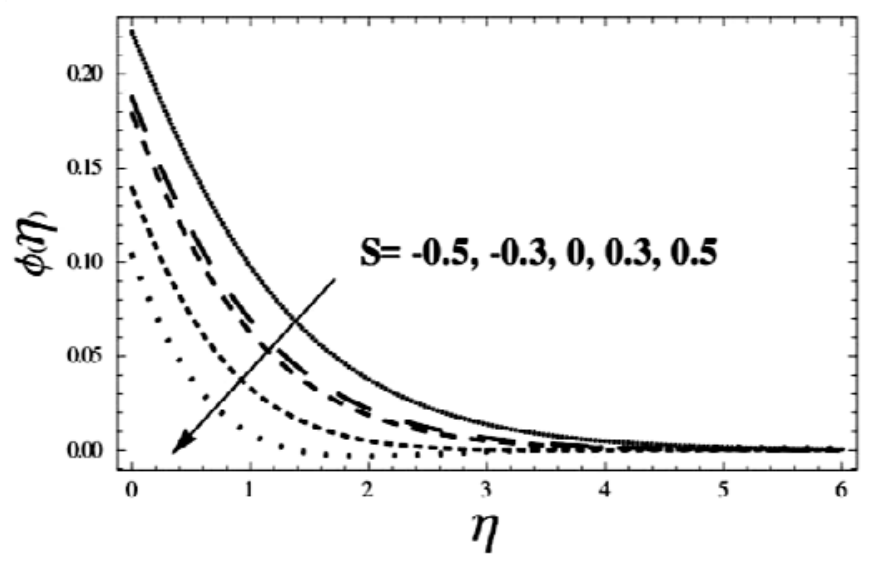

Fig.10. Effect of $S$ on nanoparticle volume fraction.

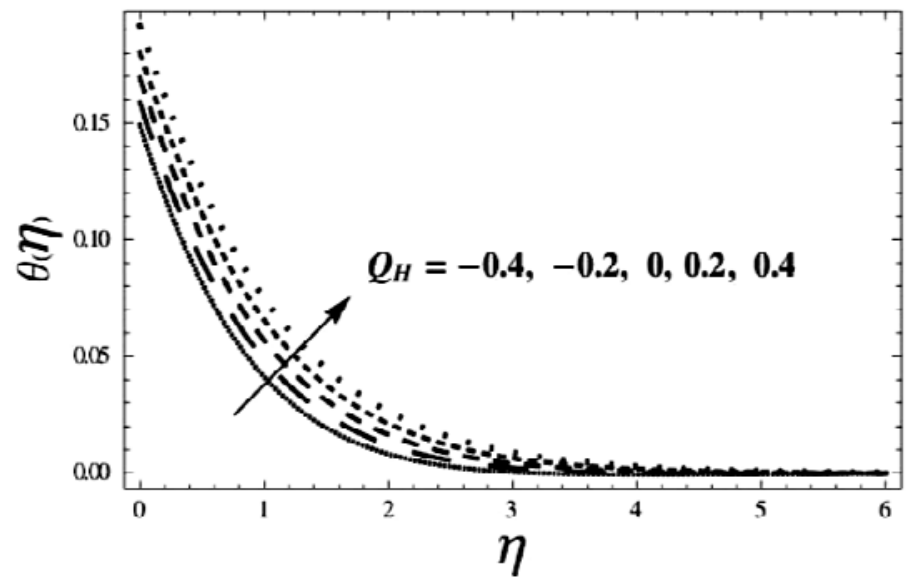

Fig.11. Effect of $Q_{H}$ on temperature.

The effect of Brownian motion parameter $N b$ on temperature is plotted in Fig.12. As the Brownian motion parameter $\mathrm{Nb}$ increases, the random motion of the fluid particles increases which results in more heat. Hence the temperature increases. The chracteristics of the thermophoresis parameter $N t$ on the temperature is presented in Fig.13 .Thermophoresis is a mechanism in which small particles are pulled away from a hot surface to a cold one. As a result it raises the temperature.The behavior of the Brownian motion parameter $\mathrm{Nb}$ on the nanoparticle volume fraction is displayed in Fig.14. The increasse in $N b$ the random motion and also collision of the macroscopic particles of the fluid increase which reduces the concentration of the fluid. Figure 15 describes the variation of the thermophoresis parameter $N t$ on the nanoparticle volume fraction. The bigger value of $N t$ coincides with the stronger thermophoretic diffusion which blows the 
nanoparticles away from the hot surface towards the cold ambient fluid. As a result, the nanoparticle volume fraction is thicker for larger values of $N t$.

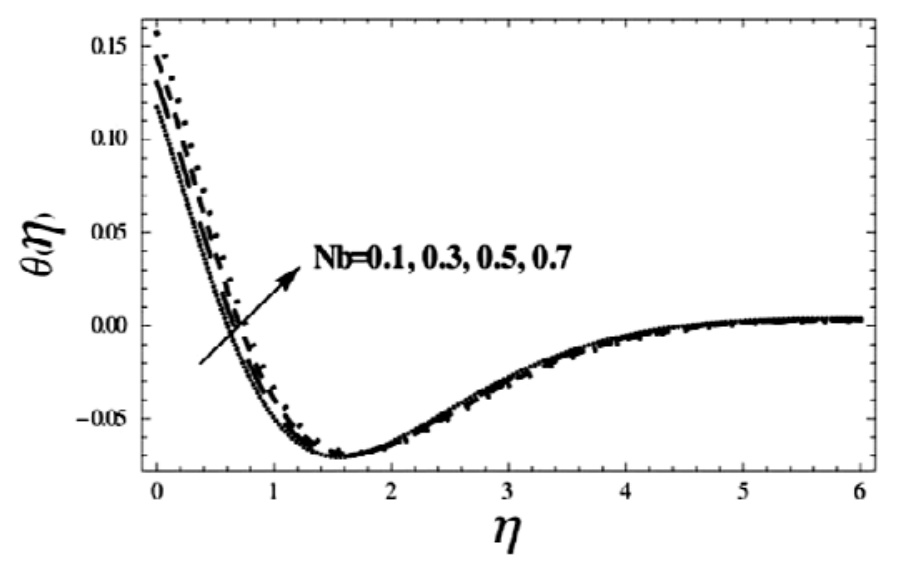

Fig.12. Effect of $N b$ on temperature.

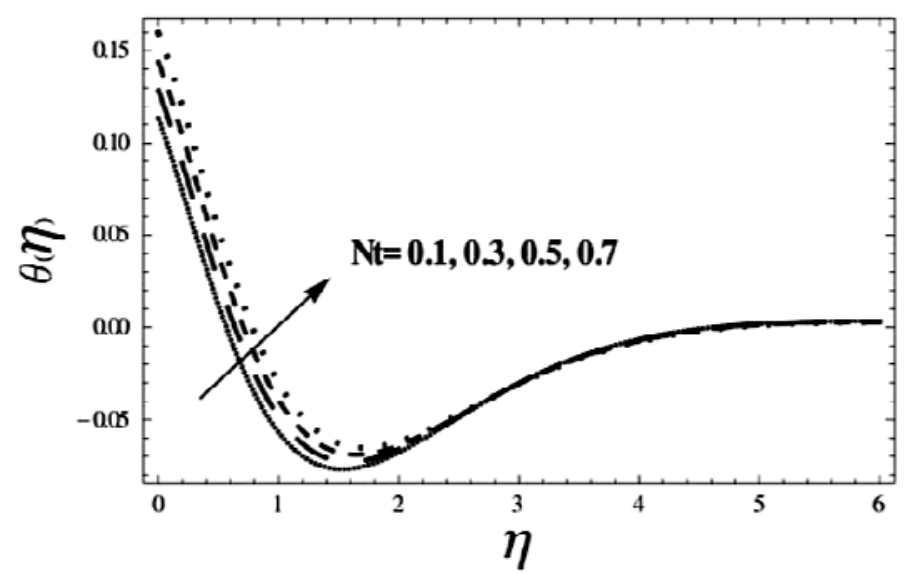

Fig.13. Effect of $N t$ on temperature.

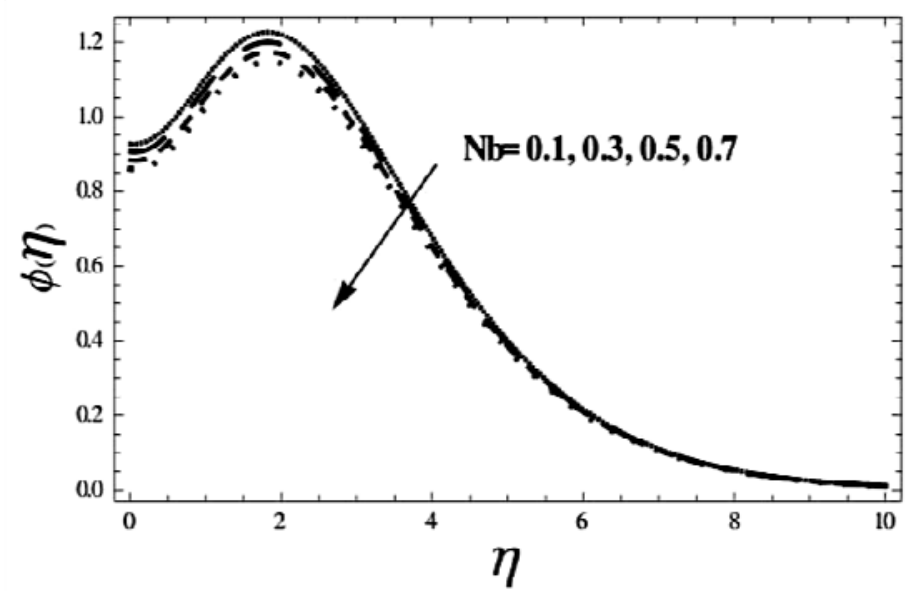

Fig.14. Effect of $N b$ on nanoparticle volume fraction. 


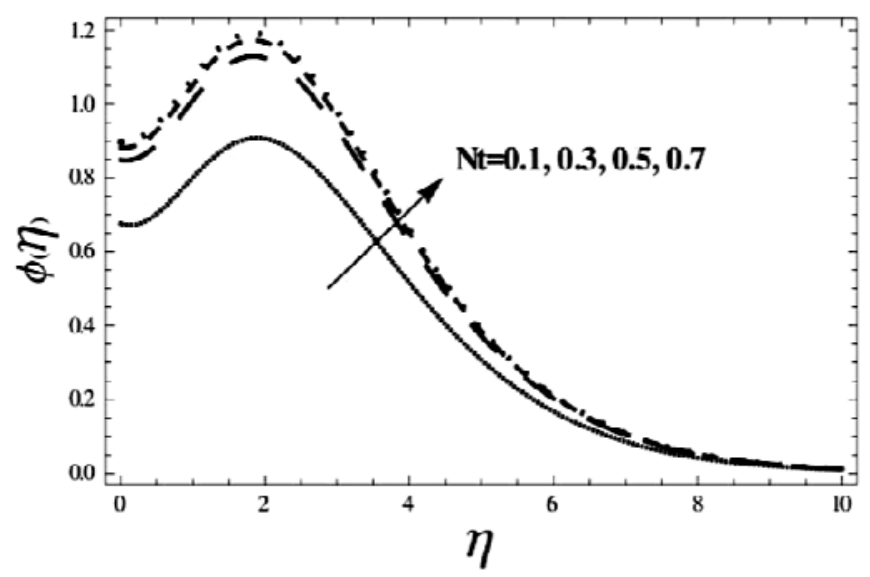

Fig.15. Effect of $N t$ on nanoparticle volume fraction.

Figure 16 depicts the nanoparticle volume fraction profiles for the variable chemical reaction parameter $\beta$.It can be seen that the nanoparticle volume fraction decreases when the chemical reaction parameter $\beta$ increases. The destructive chemical reaction $(\beta>0)$ causes a decrease of the nanoparticle volume fraction and the constructive chemical reaction $(\beta<0)$ results in an increase of the nanoparticle volume fraction. This is because the conversion of the species takes place as a result of a chemical reaction and thereby reduces the concentration in the boundary layer.

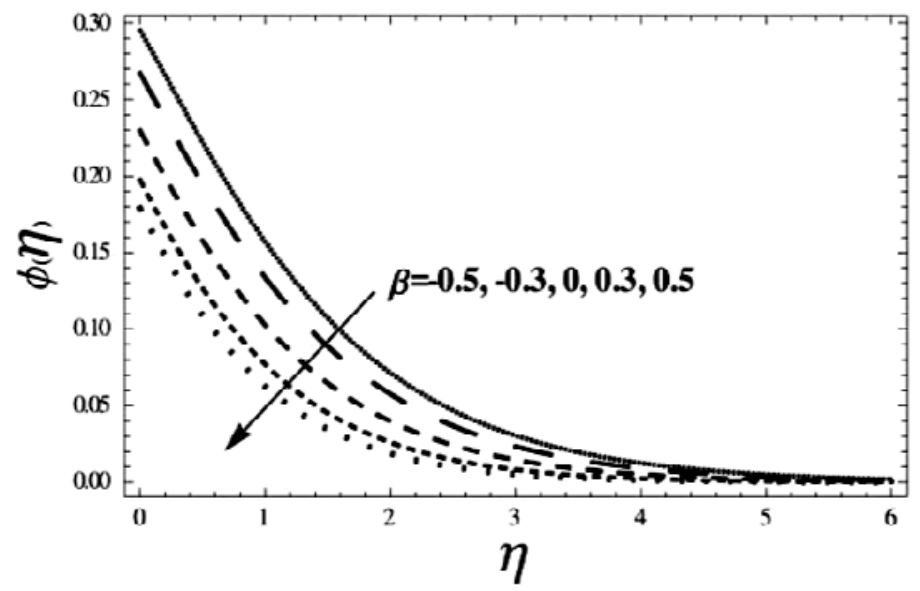

Fig.16. Effect of $\beta$ on nanoparticle volume fraction.

Figure 17 shows the influence of the heat transfer Biot number $\gamma_{1}$ on the temperature distribution. The heat transfer Biot number is defined as a ratio of convection heat transfer to the conduction heat transfer at the surface. It generally depends on the characteristic length of the surface, thermal conductivity of the surface and convective heat transfer coefficient of the hot fluid below the surface. A higher heat transfer Biot number indicates a less conductive substance such as plastic, paper, polymer, etc. on the other hand, the Biot number is small for a higher conductive materials which include aluminum, ion and steel, etc. For increasing values of the heat transfer Biot number $\gamma_{l}$, the heat transfer coefficient $h_{l}$ increases which yields heat which leads to an incease of temperature. Figure 18 depects the effect of the heat transfer Biot number $\gamma_{1}$ on the nanoparticle volume fraction. The higher surface temperature corresponding to a larger heat transfer Biot number energizes nanoparticles in the vicinity of the sheet. In order to release that additional energy, the 
nanoparticles travel away from the stretching wall. This results in a larger penetration depth of nanoparticle concentration.

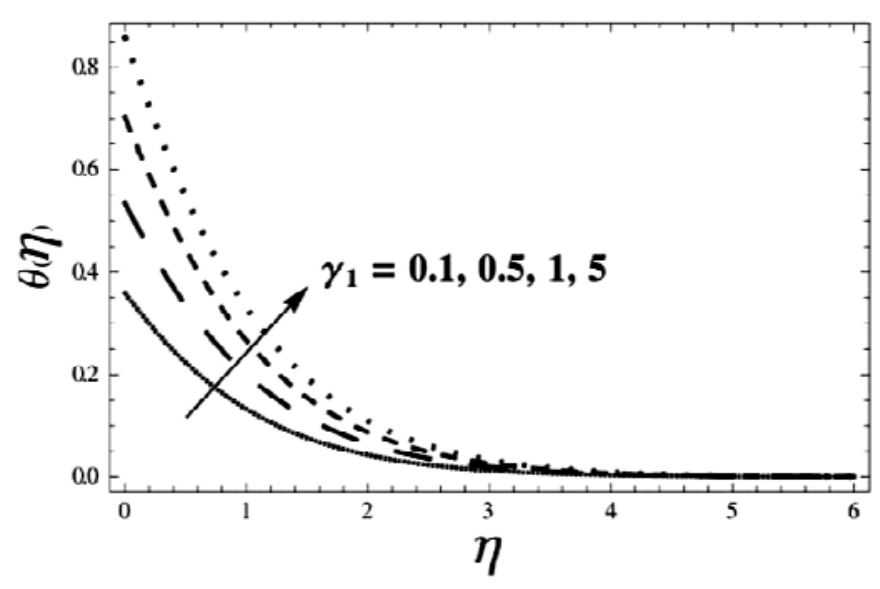

Fig.17. Effect of $\gamma_{1}$ on temperature.

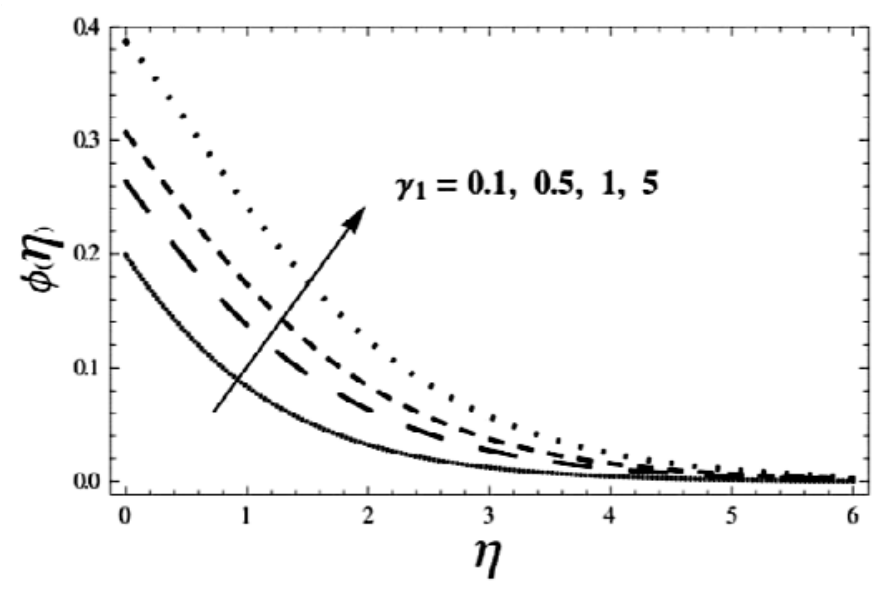

Fig.18. Effect of $\gamma_{1}$ on nanoparticle volume fraction.

The influence of the mass transfer Biot number $\gamma_{2}$ on the temperature is examined in Fig.19. Here the temperature is inceased by increasing the mass transfer the Biot number $\gamma_{2}$. Biot number $\gamma_{2}$ depends on the mass transfer coefficient $h_{2}$. The mass transfer coefficient $h_{2}$ is increased when we increase the values of the Biot number $\gamma_{2}$ due to which the temperature and thermal boundary layer thickness are enhanced. Figure 20 shows elucidate that the nanoparticle volume fraction is increasing when the values of the mass transfer Biot number $\gamma_{2}$ are increased. 


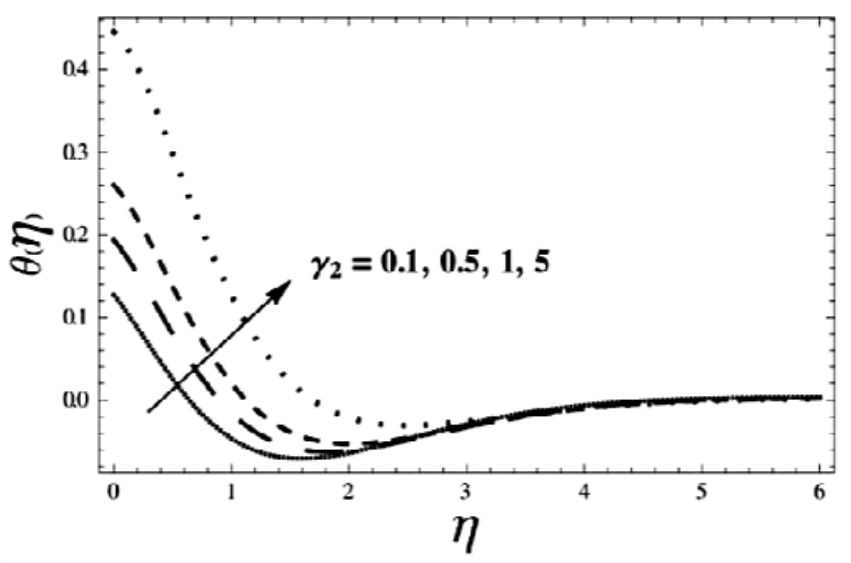

Fig.19. Effect of $\gamma_{2}$ on temperature.

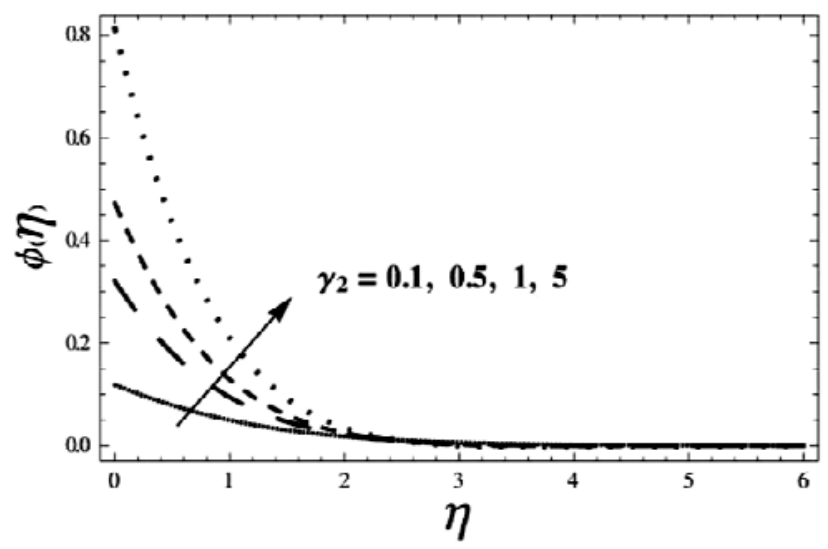

Fig.20. Effect of $\gamma_{2}$ on nanoparticle volume fraction.

Table 3 exhibits the nature of the reduced skin friction, Nusselt number and nanoparticle Sherwood number with the local magnetic parameter $M$. It is found that the reduced skin-friction increases whereas the reduced Nusselt number and nanoparticle Sherwood number decrease with increasing the local magnetic parameter $M$. Table 4 presents the effect of heat source/sink $Q_{H}$ on the reduced Nusselt number. It is clear that the Nusselt number increases with increasing the heat absorption (sink) $\left(Q_{H}<0\right)$ but decreases with increasing the heat generation (source) $\left(Q_{H}>0\right)$. The effect of the chemical reaction parameter $\beta$ on the reduced nanoparticle Sherwood number is presented in Tab.5. It can be observed that the nanoparticle Sherwood number decreases with increasing the constructive chemical reaction $(\beta<0)$ and increases with increasing the destructive chemical reaction $(\beta>0)$.

Table 3. Effect of the local magnetic parameter $M$ on the reduced skin-friction, Nusselt number and nanoparticle Sherwoodnumber.

\begin{tabular}{cccc}
\hline$M$ & $f^{\prime \prime}(0)$ & $-\theta^{\prime}(0)$ & $-\phi^{\prime}(0)$ \\
\hline 0.1 & -1.43837 & 0.15039 & 0.14307 \\
0.2 & -1.47535 & 0.15009 & 0.14295 \\
0.3 & -1.51133 & 0.14981 & 0.14285 \\
\hline
\end{tabular}


Table 4. Effect of the heat source/sink parameter $Q_{H}$ on the reduced Nusselt number.

\begin{tabular}{cc}
\hline$Q_{H}$ & $-\theta^{\prime}(0)$ \\
\hline-0.2 & 0.16746 \\
-0.1 & 0.16449 \\
0.0 & 0.16079 \\
0.1 & 0.15616 \\
0.2 & 0.15029 \\
\hline
\end{tabular}

Table 5. Effect of the chemical reaction parameter $\beta$ on the reduced nanoparticle Sherwood number.

\begin{tabular}{lc}
\hline$\beta$ & $-\phi^{\prime}(0)$ \\
\hline-0.2 & 0.08986 \\
-0.1 & 0.10273 \\
0.0 & 0.11312 \\
0.1 & 0.12158 \\
0.2 & 0.12852 \\
\hline
\end{tabular}

\section{Conclusions}

The governing equations for the steady MHD mixed convective heat and mass transfer flow over a porous exponentially stretching sheet with heat source/sink and chemical reaction effect under suction/blowing and convective boundary conditions were formulated. The resulting partial differential equations were transformed into a set of ordinary differential equations using the similarity transformations. These non-linear coupled ordinary differential equations were solved by employing the homotopy analysis method. The conclusions of the study are as follows:

1. The velocity, skin-friction, Nusselt number and nanoparticle Sherwood number decrease, whereas the temperature and nanoparticle volume fraction increase with an increase in the magnetic parameter $M$.

2. An increase in suction $(S>0)$ reduces the velocity, temperature and nanoparticle volume fraction, whereas an increase in blowing $(S<0)$ increases the velocity, temperature and nanoparticle volume fraction.

3. Both the temperature and nanoparticle volume fraction increase with an increase in either the heat transfer Biot number $\gamma_{1}$ or mass transfer Biot number $\gamma_{2}$.

4. An increase in heat source $\left(Q_{H}>0\right)$ increases the temperature and decreases the Nusselt number, whereas an increase in heat $\operatorname{sink}\left(Q_{H}<0\right)$ increases the Nusselt number and decreases the temperature.

5. Both the nanoparticle volume fraction and nanoparticle Sherwood number decrease with an increase in the constructive chemical rection $(\beta>0)$ and increase with an increase of the destructive chemical reaction $(\beta<0)$.

\section{Nomenclature}

$C$ - nanoparticle concentration $\left[\mathrm{Kg} \mathrm{m}^{-3}\right]$

$C_{\infty}$ - nanoparticles concentration far away from the surface $\left[\mathrm{Kg} \mathrm{m}^{-3}\right]$

$D_{B} \quad$ - Brownian diffusion coefficient $\left[\mathrm{m}^{2} \mathrm{~s}^{-1}\right]$

$D_{T} \quad$ - thermophoretic diffusion coefficient $\left[\mathrm{m}^{2} \mathrm{~s}^{-1}\right]$ 
$k-$ thermal conductivity $\left[\mathrm{Wm}^{-1} \mathrm{~K}^{-1}\right]$

$k_{r}$ - chemical reaction parameter

$Q$ - dimensional heat generation/absorption coefficient

$q_{r} \quad$ - radiative heat flux $\left[\mathrm{Wm}^{-2}\right]$

$T$ - fluid temperature $[K]$

$T_{\infty} \quad$ - temperature far away from the surface $[K]$

$U-$ reference velocity $\left[\mathrm{ms}^{-1}\right]$

$u, v$ - components of velocity in the $x$ and $y$ directions $\left[\mathrm{ms}^{-1}\right]$

$V_{0} \quad$ - initial strength of suction

$\lambda_{1}-$ relaxation time of the Maxwell fluid $\left[s^{-1}\right]$

$\mu-$ dynamic viscosity

$\rho_{f} \quad$ - density of the base fluid $\left[\mathrm{Kg} \mathrm{m}^{-3}\right]$

$\sigma \quad$ - electrical conductivity of the fluid $\left[\mathrm{s} \mathrm{m}^{-1}\right]$

$\tau=(\rho c)_{p} /(\rho c)_{f}-$ ratio of the effective heat capacity of the nanoparticle material to the effective heat capacity of the fluid

$v\left(=\mu / \rho_{f}\right) \quad-$ kinematic viscosity

superscript

' - primes denote differentiation with respect to $\eta$

subscripts

$$
\begin{aligned}
& f \text { - base fluid } \\
& p \text { - nano particle }
\end{aligned}
$$

\section{References}

[1] Anderson H.I., Hansen O.R. and Holmedal B. (1994): Diffusion of a chemically reactive species from a stretching sheet. - Int. J. of Heat Mass Transfer, vol.37, No.4, pp.659-664.

[2] Xu H. and Liao S.J. (2009): Laminar flow and heat transfer in the boundary-layer of non-Newtonian fluids over a stretching flat sheet. - Comput. Math. Appl., vol.57, pp.1425-1431.

[3] Mukhopadhyay S. (2013): Casson fluid flow and heat transfer over a nonlinearly stretching surface. - Chin. Phys. B 22, No.7, 074701.

[4] Prasad K.V., Santhi., S.R. and Datti P.S. (2012): Non-Newtonian power-law fluid flow and heat transfer over a non-linearly stretching surface. - Appl. Math., vol.3, No.5, pp.425-435.

[5] Wu J. and Thompson M.C. (1996): Non-Newtonian shear-thinning flows past a flat plate. - J. Non-Newton. Fluid Mech., vol.66, pp.127-144.

[6] Vieru D., Fetecau C. and Fetecau C. (2008): Flow of a viscoelastic fluid with fractional Maxwell model between two side walls perpendicular to a plate. - Appl. Math. Comput., vol.200, pp.459-464.

[7] Fetecau C., Jamil M., Fetecau C. and Siddique I. (2009): A note on the second problem of Stokes for Maxwell fluids. - Int. J. of Non-Linear Mech., vol.44, pp.1085-1090.

[8] Fetecau C., Athar M. and Fetecau C. (2009): Unsteady flow of generalized Maxwell fluid with fractional derivative due to a constantly accelerating plate. - Comput. Math. Appl., vol.57, pp.596-603.

[9] Hayat T., Fetecau C. and Sajid M. (2008): On MHD transient flow of a Maxwell fluid in a porous medium and rotating frame. - Phys. Lett. A 372, pp.1639-1644. 
[10] Bataller R.C. (2007): Effects of heat source/sink, radiation and work done by deformation on flow and heat transfer of a viscoelastic fluid over a stretching sheet. - Comput. Math. Appl., vol.53, pp.305-316.

[11] Abel M.S. and Nandeppanavar Mahantesh M. (2009): Heat transfer in MHD viscoelastic boundary layer flow over a stretching sheet with nonuniform heat source/sink. - Commun Nonlinear Sci Numer Simul., vol.14, pp.2120-2131.

[12] Mukhopadhyay S. (2012): Heat transfer analysis for unsteady flow of a Maxwell fluid over a stretching surface in the presence of a heat source/sink. - Chinese Phy. Lett., vol.29, No.5, pp.054703.

[13] Andersson H.I., Hansen O.R. and Holmedal B. (1994): Diffusion of a chemically reactive species from a stretching sheet. - Int. J. of Heat Mass Transfer, vol.37, pp.659-664.

[14] Cortell R. (2007): Toward an understanding of the motion and mass transfer with chemically reactive species for two classes of viscoelastic fluid over a porous stretching sheet. - Chem. Engng. Processing: Process Intensification, vol.46, pp.982-989.

[15] Hayat T., Awais M., Qasim M. and Hendi A.A. (2011): Effects of mass transfer on the stagnation point flow of an upper-convected Maxwell (UCM) fluid. - Int. J. of Heat and Mass Transfer, vol.54, pp.3777-3782.

[16] Mukhopadhyay S. and Bhattacharyya K. (2012): Unsteady flow of a Maxwell fluid over a stretching surface in presence of chemical reaction. - J. of the Egyptian Math. Society, vol.20, pp.229-234.

[17] Choi SUS. (1995): Enhancing thermal conductivity of fluids with nanoparticles. - ASME, USA, pp.99-105.

[18] Buongiorno J. (2006): Convective transport in nanofluids. - J. of Heat Transf., vol.128, pp.240-250.

[19] Khan W.A. and Pop I. (2010): Boundary-layer flow of a nanofluid past a stretching sheet. - Int. J. Heat Mass Transf., vol.53, pp.2477-2483.

[20] Turkyilmazoglu M. (2012): Exact analytical solutions for heat and mass transfer of MHD slip flow in nanofluids. - Chem. Eng. Sci., vol.84, pp.182-187.

[21] Hayat T., Muhammad T., Alsaedi A. and Alhuthali M.S. (2015): Magnetohydrodynamic three-dimensional flow of viscoelastic nanofluid in the presence of nonlinear thermal radiation. - J. Magn. Magn. Mater., vol.385, pp.222-229.

[22] Ashraf M.B., Hayat T. and Alsaedi A. (2015): Three-dimensional flow of Eyring-Powell nanofluid by convectively heated exponentially stretching sheet. - Eur. Phys. J. Plus, vol.5, pp.130-142.

[23] Zhang C., Zheng L., Zhang X. and Chen G. (2015): MHD flow and radiation heat transfer of nanofluids in porous media with variable surface heat flux and chemical reaction. - Appl. Math. Model., vol.39, pp.165181.

[24] Hayat T., Muhammad T., Shehzad S.A. and Alsaedi A. (2015): Similarity solution to three dimensional boundary layer flow of second grade nanofluid past a stretching surface with thermal radiation and heat source/sink. - AIP Adv., vol.5, 017107.

[25] Liao Sj. (2003): Beyond perturbation: introduction to homotopy analysis method. - Boca Raton: Chapman \& Hall/CRC Press.

[26] Liao Sj. (1992): The proposed homotopy analysis technique for the solution of non-linear problems. - Ph. D. Thesis; Shanghai Jiao Tong University.

[27] Mustafa M., Junaid Ahmad Khan, Hayat T. and Alsaedi A. (2015): Simulations for Maxwell fluid flow past a convectively heated exponentially stretching sheet with nanoparticles. - AIP Adv., vol.5, 037133.

[28] Hayat T., Taseer Muhammad, Shehzad S.A. Chen G.Q. and Ibrahim A. Abbas (2015): Interaction of magnetic field in flow of Maxwell nanofluid with convective effect. - Journal of Magnetism and Magnetic Materials, vol.389, pp.48-55.

[29] Brewster M.Q. (1972): Thermal Radiative Transfer Properties. - John Wiley and Sons. 
[30] Liao Sj. (2012): Homotopy analysis method in nonlinear differential equations. - Beijing and Heidelberg: Higher Education Press and Springer.

[31] Mustafa M., Ahmad Khan J., Hayat T. and Alsaedi A. (2015): Sakiadis flow of Maxwell fluid considering magnetic field and convective boundary conditions. - AIP Adv., vol.5, 027106.

[32] Ramesh G.K. and Gireesha B.J. (2014): Influence of heat source/sink on a Maxwell fluid over a stretching surface with convective boundary condition in the presence of nanoparticles. - Ain Shams Engineering Journal, vol.5, pp.991-998.

[33] Chamka A.J., Rashad A.M. and Ram Reddy Ch. (2014): Murthy, PVSN, Effect of suction/injuction on free convection along a vertical plate in a nanofluid saturated non-Darcy porous medium with internal heat generation. - Indian J. Pure Appl. Math., vol.45, No.3, pp.321-341.

[34] Shehzad S.A., Hayat T. and Alsaedi A. (2015): Influence of convective heat and mass conditions in MHD flow of nanofluid. - Bulletin of the Polish Academy of Sciences Technical Sciences, vol.63, DOI: 10.1515/bpasts2015-0053.

[35] Swati Mukhopadhyay, Krishnendu Bhattacharyya and Layek G.C. (2014): Mass Transfer over an Exponentially Stretching Porous Sheet Embedded in a Stratified Medium. - Chem. Eng. Comm., vol.201, pp.272-286.

[36] Magyari E. and Keller B. (1999): Heat and mass transfer in the boundary layer on an exponentially stretching continuous surface. - J. Phys. D. Appl. Phys., vol.32, pp.577-585.

Received: December 1, 2016

Revised: October 20, 2017 